\title{
Violência obstétrica: percepção dos enfermeiros da estratégia de saúde a família
}

Identificar a percepção referente à Violência Obstétrica dos enfermeiros atuantes na atenção básica do município de Cáceres, do estado de Mato Grosso. Tratase de uma pesquisa descritiva, exploratória de abordagem qualitativa, com os enfermeiros atuantes na Atenção Básica que realizam atendimentos com gestantes. A análise dos dados foi feita de acordo com a técnica de Análise de Conteúdo de Minayo, respeitando as 03 etapas de análise. Mediante as falas dos enfermeiros, foi possível observar que possuíam compreensão de que a Violência Obstétrica vai além da agressão física como também de ações psicológicas e são cientes que aspectos socioculturais de cada profissional influenciam nessa ocorrência. Porém é valido destacar também que alguns profissionais possuem certa fragilidade em identificar a Violência Obstétrica, fator preocupante, pois muitas vezes podem deixar passar despercebidos casos, por considerarem que somente ocorre a Violência Obstétrica no ambiente hospitalar. Conclui-se que os profissionais enfermeiros da rede da atenção básica vêm buscando compreender melhor sobre Violência Obstétrica, suas várias apresentações e formas de mitigação desta ocorrência com suas clientes assistidas. Ressalta-se que investir no treinamento dos profissionais que assistem à mulher em seu processo de parturição faz necessário.

Palavras-chave: Enfermagem; Saúde da Mulher; Estratégia Saúde da Família.

\section{Obstetric violence: nurses' perception of the family health strategy}

To identify the perception regarding the Obstetric Violence of nurses working in primary care in the municipality of Cáceres, in the state of Mato Grosso. This is a descriptive, exploratory study with a qualitative approach, with nurses working in Primary Care who provide care to pregnant women. Data analysis was performed according to Minayo's Content Analysis technique, respecting the 03 stages of analysis. Through the nurses' statements, it was possible to observe that they had an understanding that Obstetric Violence goes beyond physical aggression as well as psychological actions and they are aware that the sociocultural aspects of each professional influence this occurrence. However, it is also worth noting that some professionals have a certain weakness in identifying Obstetric Violence, a worrying factor, as they can often overlook cases, as they consider that Obstetric Violence only occurs in the hospital environment. It is concluded that the professional nurses in the primary care network have been seeking to understand better about Obstetric Violence, its various presentations, and ways of mitigating this occurrence with its assisted clients. It is emphasized that investing in the training of professionals who assist women in their parturition process makes it necessary.

Keywords: Nursing; Women's Health; Family Health Strategy.

Topic: Enfermagem Obstétrica

Reviewed anonymously in the process of blind peer.
Received: 05/02/2021

Approved: 21/04/2021
Rosiéle Campos Brum da Silva (iD)

Universidade do Estado de Mato Grosso, Brasil http://lattes.cnpq.br/6836498922145449 http://orcid.org/0000-0002-9853-3846 rsecampos15@gmail.com

\section{Joselaine Souto Hall Silva (it)}

Universidade do Estado de Mato Grosso, Brasil http://lattes.cnpq.br/2607621597856798 http://orcid.org/0000-0001-5667-8871 joselaineshs@unemat.br

\section{Julia Salome de Souza (iD}

Universidade do Estado de Mato Grosso, Brasil http://lattes.cnpq.br/0297945434662766 http://orcid.org/0000-0003-1909-6949 juhsalome@yahoo.com.br
Natasha Rayane de Oliveira Lima (iD) Universidade do Estado de Mato Grosso, Brasil http://lattes.cnpq.br/9449797453342327 http://orcid.org/0000-0002-4547-0263 natasharayane@hotmail.com

Kesia Marisla Rodrigues da Paz

Universidade do Estado de Mato Grosso, Brasil http://lattes.cnpq.br/9598944284275446 http://orcid.org/0000-0003-2727-8427 kmrpaz@unemat.br

Amaly Vidal Aziz (iD

Universidade do Estado de Mato Grosso, Brasil http://lattes.cnpq.br/7759234030405025 http://orcid.org/0000-0002-8871-1258 amaly.cac@gmail.com
Noely Machado Vieira (D)

Universidade do Estado de Mato Grosso, Brasil http://lattes.cnpq.br/4720289798017017 http://orcid.org/0000-0002-3705-7006 noelyenf@outlook.com

\section{Bianca Teshima de Alencar (iD)}

Universidade do Estado de Mato Grosso, Brasil http://lattes.cnpq.br/9101535074774508 http://orcid.org/0000-0001-6812-3494 biateshima@hotmail.com

\section{Referencing this:}

SILVA, R. C. B.; SILVA, J. S. H.; SOUZA, J. S.; LIMA, N. R. O.; PAZ, K. M. R.; AZIZ, A. V.; VIEIRA, N. M.; ALENCAR, B. T.. Violência obstétrica: percepção dos enfermeiros da estratégia de saúde a família. Scire Salutis, v.11, n.2, p.75-82, 2021. DOI:

http://doi.org/10.6008/CBPC2236-9600.2021.002.0008 


\section{INTRODUÇÃO}

A assistência obstétrica tem sofrido modificações ao longo dos últimos séculos em todo o mundo. O parto, antes visto como um evento fisiológico e familiar, atendido por parteiras no domicílio, passou a ser institucionalizado, se tornando um evento patológico que necessita de intervenção médica para acontecer de maneira mais segura. A medicalização do parto submete a mulher com maior frequência a intervenções cirúrgicas e desnecessárias do ponto de vista da Medicina Baseada em Evidência, com o discurso social de que dessa forma, o binômio mãe-bebê não sofreria, sendo possível a diminuição das taxas de mortalidade materna e neonatal, o que na prática, não acontece (ZANARDO et al., 2017).

Esta institucionalização e medicalização do parto acarretam práticas mecânicas e fragmentadas, com excesso de intervenções desnecessárias que não levam em consideração a Medicina Baseada em Evidência, e retira a autonomia feminina sobre o próprio corpo, violando direitos sexuais e reprodutivos (LEAL et al., 2018).

Neste cenário, a violência institucional direcionada a mulher ocorre gradativamente, impondo preconceitos direcionados ao corpo feminino, de ser o sexo frágil, sendo evidenciadas pela ausência de informações e respeito dos procedimentos a serem feitos, o que desonra sua dignidade, e corresponde à representatividade da expressão Violência Obstétrica (VO) durante o período gravídico-puerperal (ZANARDO et al., 2017).

O termo VO vem sendo definido como a apropriação por parte dos profissionais de saúde, do corpo feminino e da autonomia reprodutiva da mulher durante o pré-natal, parto e pós-parto, expondo-a a condutas desumanizadas, procedimentos constrangedores e dolorosos, medicações desnecessárias e atitudes abusivas na esfera psicológica, transformando dessa maneira, o processo natural do nascimento em patológico (SENA et al. 2017).

No Brasil, diante da exposição de violência direcionada ao sexo feminino, o Ministério da Saúde (MS) lança políticas públicas que visem assegurar o bem estar da mulher, através da Política Nacional de Atenção Integral da Saúde da Mulher (PNAISM) que direciona a mulher como fonte de estudo em sua alta complexidade, permitindo uma ação continuada na assistência na atenção básica para o enfrentamento da VO. Segundo o MS, estes programas buscam assegurar: tratamentos livres de danos e maus tratos, obtenção de informações sobre os procedimentos realizados, garantia do direito de possuir o acompanhante durante o período de internação, garantir atendimento multidisciplinar qualificado, tratamentos amparados pelas diretrizes do Sistema Único de Saúde (SUS) e ser livre de discriminações raciais, socioeconômicos, e culturais (MATOSO, 2018).

Apesar do incentivo do governo, dados epidemiológicos alarmantes apontam que uma a cada quatro mulheres sofreram violência obstétrica durante o trabalho de parto, tais como: episiotomia de rotina, ocitocina sem indicação para todas as mulheres, manobra de kristeller, agressões verbais e psicológicas, proibição da presença do acompanhante, jejum de rotina, dentre outros (SENA e TESSER, 2017). Ainda, conforme a Fundação Perseu Abramo (FPA), 25\% das mulheres no Brasil já sofreram algum tipo de VO institucional seja em redes públicas ou privadas, e estes se iniciaram durante o período de 
acompanhamento de pré-natal e se agravando durante o momento de parto e pós-parto ou situações de aborto (FPA, 2010).

Dessa forma, a abordagem durante o pré-natal sobre a VO se faz relevante numa tentativa de minimizar a incidência de casos que possam ser perpetuados contra gestantes e parturientes nas instituições públicas e privadas. A assistência a gestante no pré-natal deve abordar temas que possam constranger as mulheres, mais que devem ser trabalhadas de forma clara e objetiva, criando o empoderamento sobre seus direitos durante o ciclo gravídico-puerperal, tornando-as participativas no processo de escolha do parto, diminuindo a probabilidade de ocorrência de violência institucional obstétrica (MOURA et al., 2015).

Neste sentido, a Atenção Básica, materializada nas Unidades de Saúde da Família (USF), tem importância fundamental, como porta de entrada no sistema de saúde para gestantes. A captação precoce dessa gestante, somada ao acolhimento, educação em saúde e pré-natal de qualidade juntos podem ajudar a transformar esta realidade. Em 2017, o Ministério da Saúde lançou no Brasil, as novas diretrizes de assistência ao parto normal. Este documento orienta que os profissionais de saúde durante as consultas de pré-natal, devem informar as mulheres sobre riscos e benefícios de inúmeras práticas e intervenções durante o trabalho de parto e parto (BRASIL, 2017).

Estudos mostram que a falta de informação e o medo de questionar os profissionais de saúde durante o trabalho de parto sobre os procedimentos realizados, deixam mulheres a mercê de serem vítimas de VO (LEAL et al., 2018).

Nas USF, o pré-natal deve ser conduzido pelo médico e pelo enfermeiro, em consultas intercaladas, sendo o enfermeiro o profissional com embasamento técnico-científico e respaldo legal para conduzir o pré-natal de risco habitual, realizando educação em saúde durante as consultas. A atuação do profissional enfermeiro durante o pré-natal deve garantir uma assistência segura, possibilitando através da transmissão de conhecimento, a sensibilização da mulher com redução dos riscos de ocorrência de VO (PIO et al., 2015).

Considerando o número ainda alarmante de mulheres que sofrem violência obstétrica e o potencial do enfermeiro de ofertar conhecimento para as gestantes durante as consultas de enfermagem no prénatal, como forma de empoderar as mulheres diminuindo os casos de violência obstétrica, este estudo se propôs a identificar a percepção de enfermeiros atuantes na Atenção Básica do município de Cáceres-MT acerca da violência obstétrica.

\section{METODOLOGIA}

Trata-se de uma pesquisa de campo, descritiva, exploratória de abordagem qualitativa, realizada nas Unidades de Saúde da Família (USF), do município de Cáceres, Mato Grosso. O município conta com 16 USF, sendo 11 delas localizadas no núcleo urbano e os demais na zona rural.

A população alvo foi composta por enfermeiros atuantes na Atenção Básica que realizam consulta pré-natal com gestantes, e que atendessem os critérios de inclusão e exclusão. Foram critérios de Inclusão: ser enfermeiro, desejar participar da pesquisa, trabalhar em Unidades de Saúde da Família da zona urbana 
e assinar o Termo de Consentimento Livre e Esclarecido (TCLE). Os critérios de exclusão: responder menos de $80 \%$ dos questionamentos, ser Unidade de Saúde da Família de zona rural e não assinar o TCLE. Dessa forma, após receberem todas as informações sobre a finalidade da pesquisa, e assinarem o TCLE o estudo contou com 8 participantes.

A coleta de dados ocorreu entres os meses de agosto a setembro de 2020, por meio da aplicação de um formulário padronizado e semiestruturado, contendo perguntas norteadoras referente ao conhecimento do entrevistado referente a VO e as medidas de enfrentamento que ele como profissional enfermeiro tomaria frente esse agravo. Para garantir a confidencialidade dos participantes, foram utilizados pseudônimos discriminados pela letra ' $P$ ' (participante), seguidos por um número, de acordo com a sequência das entrevistas.

A análise dos dados foi feita de acordo com a técnica de Análise de Conteúdo proposto por Minayo (2014), a qual permite a organização dos conteúdos em categorias e por agrupamentos das ideias que atendem aos objetivos do estudo. Foram respeitadas e realizadas as três etapas de análise: a) Pré-análise, que permitiu um contato direto com os dados coletados, garantindo assim algumas normas de validade qualitativa (exaustividade, representatividade, homogeneidade e pertinência). b) No segundo momento foi feita a exploração do material, que consistiu no processo de classificação, por meio da técnica de 'colorimetria', em que foram destacadas as falas que possuíam semelhanças e distinções sobre a mesma pergunta norteadora, sendo identificadas mediante a utilização de diferentes cores; c) Por fim, foram definidas categorias que abrangiam elementos e aspectos com características comuns ou que se relacionavam entre si conforme sua pertinência e presença do tema, apontando estrutura de relevância para o objetivo proposto na pesquisa. Realizou-se a discussão/tratamento dos resultados e a interpretação, buscando desvendar o conteúdo subjacente ao que estava sendo manifesto, estabelecendo articulações entre os dados e a literatura pertinente.

A pesquisa foi submetida à apreciação do Comitê de Ética em Pesquisa da Universidade do Estado de Mato Grosso - UNEMAT, obtendo parecer favorável para sua realização, conforme número do protocolo: 4.186.011, de 31 de julho de 2020. Foram adotadas todas as diretrizes e normas regulamentadoras contidas na Resolução no 466/12 do Conselho Nacional de Saúde.

\section{DISCUSSÃO}

Dos 08 profissionais de enfermagem que participaram do presente estudo, 06 eram do sexo feminino 02 do sexo masculino. A maioria tinha idade entre 27 e 35 anos (07), e se autodeclararam pardos (06). Em relação ao vínculo empregatício dos participantes, 04 participantes possuíam tempo de atuação superior a 04 anos na atenção básica, 01 participante possuía tempo superior a 01 ano e 03 participantes possuíam tempo de até 01 ano.

Foi possível identificar na fala dos participantes a compreensão da VO como algo além da agressão física, incluindo qualquer ação que gere desconforto psicológico, causando danos de várias naturezas a mulher e seu bebê: 
algum desconforto durante o pré-natal, por exemplo, quando a gestante encontra dificuldades impostas pelo profissional durante a consulta; brincadeiras de mau gosto ou piadas; qualquer ato constrangedor é um ato Violento Obstétrico (P6). É qualquer tipo de agressão que venha colocar a gestante em sofrimento psicológico ou físico desnecessariamente (P2). É qualquer ação física e mental que venha a afeta (da) a gestação ou acarretar problemas futuros para o bebê (P3).

Esta visão abrangente do que é VO que para além dos danos físicos incluem danos de outra natureza é extremamente importante para o profissional enfermeiro, tendo em vista que este profissional na grande maioria das vezes é o contato principal da mulher, durante todo o seu período gravídicopuerperal, realizando o pré-natal. Ressalta-se a importância deste profissional estar capacitado e atualizado por meio da educação continuada permanente, afim até mesmo de ter competência para poder investigar casos de VO contra estas gestantes no ambiente domiciliar (MOURA et al., 2018).

Em outra vertente, no que diz respeito a VO que ocorre com as gestantes atendidas na atenção básica, nota-se que muitos profissionais são cientes que aspectos socioculturais e as vivências de cada influência nessa ocorrência. É válido também destacar, que alguns profissionais possuem certa fragilidade em identificar a VO, e acabam por normalizar condutas violentas na assistência, não identificando o protagonismo da mulher neste processo, considerando que a vo ocorre somente no ambiente hospitalar.

Abuso físico; verbal; discriminação com base a idade; etnia; classe social (P6). Acredito que seja pela falta de informações em relação a como a gestante será atendida nos próximos níveis de atenção a saúde, me refiro ao atendimento que acontece quando elas entram em trabalho de parto, muitas das vezes não são bem orientadas e acabam por sofrerem mais violências obstétricas (P2). Puérperas relatam abuso físico (tapas e beliscões) e abuso verbal durante a permanência nos hospitais (P1). Sinceramente não sei te responder, já que nas unidades que trabalhei não existiu algo do tipo (P5).

Em estudo de Guimarães, et al. (2018), corrobora para os achados da presente pesquisa quando traz que dentre os fatores que exercem influência e contribuem para os aumentos dos casos de Vo, encontram-se a inexecução ou realização de procedimentos de forma errônea e prejudicial à saúde da mulher e do bebê, ocorrência da negligência em prestar uma assistência de qualidade; preconceito sociocultural; ausência de informações durante o acompanhamento do pré-natal; negar direcionamento para a unidade de referência, ou a convencendo no retorno para a sua casa mesmo quando o atendimento se faz necessário.

Cabe ressaltar que o enfermeiro é o articulador das informações que serão precedidas para atuarem com êxito nos atendimentos futuros da mulher, se faz importante, para a mulher e sua família, como uma forma de proporcionar o momento único, possibilitando a reflexão da educação continuada, através das rodas de conversas; panfletos; atendimentos únicos e humanizados durante as consultas (MATOSO, 2018).

As práticas de VO quando reconhecidas por profissionais enfermeiros, podem e devem ser corrigidas com o intuito de não ocorrer à perpetuação de danos a mulher, diminuindo assim, a disposição de problemas futuros a usuária. Aceitar e saber identificar quando comete VO contra a gestante mesmo de forma não intencional é importante para que o profissional aceite sua fragilidade e busque melhorar suas 
práticas. Durante a pesquisa foi tocante às falas de que os profissionais admitiram que de alguma maneira e momento cometeram esta prática.

Não intencionalmente, mas possivelmente em algum momento tenho deixado de prestar as informações por completo (P2). Com o desconhecimento pratiquei, mas depois de orientada não mais (P4). Discriminação com base em idade, condições socioeconômicas (P7).

Quando o profissional não possui a percepção de que pode também de alguma forma ser capaz de cometer a VO, demonstra que os mesmos podem praticar com maior frequência condutas inapropriadas durante seu atendimento, tornando o atendimento menos qualificado e muito próximo de práticas de V.O (BARBOSA, et al., 2017).

Quando indagados referente à importância de um acompanhante no processo gravídicopuerperal, observou-se que $90 \%$ (06) dos participantes demonstraram estar conscientes sobre esse conhecimento e que os mesmos sabem que este é um direito amparando por lei, e apenas 10\% (01) participante, não considerava a ação de impedir o acompanhante um ato de V.O:

A Lei Federal № 11.108, de 07 de abril de 2005, conhecida como a Lei do Acompanhante que obriga a permissão á gestante o direito ao acompanhante durante todo o período de trabalho de parto, sendo o acompanhante de escolha da gestante (P6). A gestante é amparada pela lei (...) e realizo as orientações durante o atendimento, para que ela esteja ciente deste direito quando chegar ao hospital também (P4). Não considero como VO o ato de impedir a entrada do acompanhante (P8).

Qualquer usuária de saúde está assegurada em ter "direito a um acompanhante de livre escolha" em ambientes públicos e privados, sendo assegurado pela Lei Federal № 11.108, de 07 de abril de 2005, durante todo o período de trabalho de parto, parto e pós-parto. (BRASIL, 2012). Em estudo realizado referente à percepção das puérperas quanto a contribuição de um acompanhante durante o processo gravídico, demonstra a importância desde acompanhante uma vez que a presença proporciona mais conforto, acalma, minimiza sentimento de solidão e ate mesmo a dor durante o processo do parto, permitindo que a gestante se sinta mais segura e confiante, tornando o parto e nascimento do bebê uma experiência mais humanizada (DODOU et al., 2014).

A maioria dos enfermeiros participantes da pesquisa apresentaram estratégias de enfrentamento a VO que realizam no atendimento as gestantes. Destacando, sobretudo como principal ferramenta de abordagem a educação em saúde destas, por meio de rodas de conversa e também destacasse a orientação com a equipe de saúde, agentes comunitários e técnicos de enfermagem para saberem identificar a VO também durante o contato destes com as gestantes.

Promover um local propício, aconchegante e seguro para acolher as gestantes $e$ puérperas, propiciar uma agenda programada das consultas que serão realizados, garantindo o direito de acompanhante durante todo o processo de gestação através de orientações em cursos e/ou roda de conversa para a família e também orientando através de informativos e rodas de conversa sobre os direitos da gestante constituído por leis (P7).

Pelo que acho nos como enfermeiros devemos buscar mais informações atualizadas para repassar a equipe e as gestantes sobre o tema de Violência Obstétrica (...) e utilizar da roda de conversa para repassar estas orientações para as gestantes (P2).

É importante realizar capacitações com a equipe (ACS, Técnico e administrativo) sobre os direitos das gestantes e como realizar um bom acolhimento, identificando a V.O (P5). 
A área da enfermagem esta alinhado com o PNH, que permeia pela construção dos novos saberes, buscando aprimorar a melhora do acesso em saúde, realizando o resgate sobre a valorização dos envolvidos. Para que haja a melhora dos vínculos, é necessário trabalhar e priorizar a "comunicação", pois é através dela que surge a melhora do vínculo de afetividade, experiências, soluções dos problemas e resgate das soluções conjuntas, o que de forma geral, refletira no atendimento aos seus usuários (BROCA et. al, 2012).

Um ponto importante de destaque citado pelos entrevistados foi quanto à falta de capacitação que o serviço de saúde proporciona a eles, tanto no tocante de capacitá-los sobre o que é a VO quanto de como lidar com este ocorrido. Sendo este um ponto preocupante principalmente para novos profissionais que iniciam no atendimento nas unidades básicas: "Em nenhum momento desde que estou trabalhando na gestão pública foi oferecido alguma capacitação" (P2).

Nesta vertente Cardoso et al., (2017) destaca como solução importante e viável para o combate da VO se baseia na assistência humanizada a gestante, mas esta só é possível por meio da realização de atualizações dos enfermeiros e equipe que atua no cuidado a estas mulheres.

\section{CONCLUSÕES}

Evidenciou-se no presente estudo que os profissionais enfermeiros da rede da atenção básica vêm buscando compreender melhor sobre VO, suas várias apresentações e formas de mitigação desta ocorrência com suas clientes assistidas. Ressalta-se que investir no treinamento dos profissionais que assistem à mulher em seu processo de parturição faz necessário, assim como programas de educação continuada, cursos, criação e implementação de leis rígidas, notificações e apoio das instituições podem ser maneiras de minimizar tantas situações violentas durante a assistência a essa clientela.

\section{REFERÊNCIAS}

BARBOSA, N. R.; LIMA, T. Q; BARROS, L. A.; COTTA, C. F. A. (Des)conhecimento sobre a prática da violência obstétrica. Enfermagem Brasil, v.17, n.4, p.318-325, 2018.

BRASIL. Atenção ao pré-natal de baixo risco. Brasília: Ministério da Saúde, 2012

BRASIL. Diretrizes nacionais de assistência ao parto normal: versão resumida. Brasília: Ministério da Saúde, 2017.

BROCA, P. V.; FERREIRA, M. A.. Equipe de enfermagem e comunicação: contribuições para o cuidado de enfermagem. Revista Brasileira de Enfermagem, v.65, n.1, p.97-103, 2012

CARDOSO, F. J. C.; COSTA, A. C. M.; ALMEIDA, M. M.; SANTOS, T. S.; OLIVEIRA, F. B. M.. Violência obstétrica institucional no parto: percepção de profissionais da saúde. Rev enferm UFPE, v.11, n.9, p.3346-53, 2017.

MOURA, S. G.; MELO, M. M. M.; CÉSAR, E. S. R; SILVA, V. C. L.; DIAS, M. D; FILHA, M. O. F.. Assistência pré-natal realizada pelo enfermeiro (a): um olhar da mulher gestante.. Revista de Pesquisa Cuidado é Fundamental, v.7, n.3, p.2930-2938, 2015
DINIZ, S. G.; SALGADO, H. O.; ANDREZZO, H. F. A.; CARVALHO, P. G. C.; CARVALHO, P. C. A.; AGUIAR, C. A.; NIY, D. Y.. Violência obstétrica como questão para a saúde pública no Brasil: origens, definições, tipologia, impactos sobre a saúde materna, e propostas para sua prevenção. J. Hum. Growth Dev., v.25, n.3, p.377-82, 2015.

DODOU, H. D.; RODRIGUES, D. P.; GUERREIRO, E. M.; GUEDES, M. V. C.; LAGO, P. N.; MESQUITA, N. S. A.. Contribuição do acompanhante para a humanização do parto e nascimento: percepções de puérperas. Escola Anna Nery Revista de Enfermagem, v.18, n.2, p.262-269, 2014.

FBA. Mulheres brasileiras e gênero nos espaços público e privado: pesquisa de opinião pública. Fundação Perseu Abramo, 2010.

GUIMARÃES, L. B. E.; JONAS, E.; AMARAL, L. R. O.

G..Violência obstétrica em maternidades públicas do estado do Tocantins. Revista Estudos Feministas, v.26, n.1, p.1-11, 2018.

LEAL, S. Y. P.; LIMA, V. L. A.; SILVA, A. F.; SOARES, P. D. F. L.; SANTANA, R. L.; PEREIRA, A.. Percepção de enfermeiras obstétricas acerca da violência obstétrica. Cogitare 
Enfermagem, v.23, n.2, p.1-7, 2018.

MATOSO, L. M. L.. O papel do enfermeiro frente à violência obstétrica. Ciência \& Desenvolvimento: Revista Eletrônica da FAINOR, v.11, n.1, 2018

MOURA, R. C. M.; PEREIRA, F. T.; REBOUÇAS, F. J.; COSTA, C. M.; LERNADES, A. M. G.; SILVA, L. K. A.; ROCHA, K. M. M. Cuidados de enfermagem na prevenção da violência obstétrica. Enferm. Foco, v.9, n.4, p.60-65, 2018.

OLIVEIRA, T. R.; COSTA, R. E. O. L.; MONTE, N. L.; VERAS, J. M. M. F.; SÁ, M. I. M. R.. Percepção das mulheres sobre violência obstétrica. Revista de Enfermagem UFPE, v.11, n.1, p.40-46, 2017.

PIO, D. A. M.; CAPEL, M. D. S.. Os significados do cuidado na gestação. Revista Psicologia e Saúde, v.7, n.1, p.74-81, 2015.
SENA, L. M.; TESSER, C. D.. Violência obstétrica no Brasil e o ciberativismo de mulheres mães: relato de duas experiências. Interface, v.21, n.60, 2017.

VIEIRA, L. B.; PADOIN, S. M. M.; LANDERDAHL, M. C.. A percepção de profissionais da saúde de um hospital sobre a violência contra as mulheres. Revista Gaúcha de Enfermagem, v.30, n.4, p.609-616, 2009.

ZANARDO, G. L. D. P.. URIBE, M. C.; NADAL, A. H. R.; HABIGZANG, L. F.. Violencia obstétrica en brasil: una revisión narrativa. Psicologia \& Sociedade, v.29, p.1-11, 2017.

A CBPC - Companhia Brasileira de Produção Científica (CNPJ: 11.221.422/0001-03) detém os direitos materiais desta publicação. Os direitos referem-se à publicação do trabalho em qualquer parte do mundo, incluindo os direitos às renovações, expansões e disseminações da contribuição, bem como outros direitos subsidiários. Todos os trabalhos publicados eletronicamente poderão posteriormente ser publicados em coletâneas impressas sob coordenação da Sustenere Publishing, da Companhia Brasileira de Produção Científica e seus parceiros autorizados. Os (as) autores (as) preservam os direitos autorais, mas não têm permissão para a publicação da contribuição em outro meio, impresso ou digital, em português ou em tradução. 